\title{
Political and Public Perceptions of Students' Dressing Codes in Higher Learning Institutions
}

\author{
Mpawenimana Abdallah Saidi ${ }^{1}$, Robert Renatus Bujiku ${ }^{2}$, Leonard Nyanzira ${ }^{3}$, Neilson Ilan Mersat ${ }^{4}$ \\ ${ }^{1,2,3,4}$ Faculty of Social Sciences, Universiti Malaysia Sarawak (UNIMAS), Sarawak, Malaysia \\ mpawebissavp@gmail.com ${ }^{1}$
}

Article History: Received: 10 November 2020; Revised: 12 January 2021; Accepted: 27 January 2021; Published online: 05 April 2021 Abstract: This study sought to explore Politics of students' dressing codes and its impact on political and public perceptions
in Tanzanian higher learning institutions. It was a qualitative study which used an in depth interviews to collect data from 10
administrative regions (Mwanza, Arusha, Dodoma, Dar es salaam, Mbeya, Iringa, Kagera, Tanga, Mtwara and Tabora) in
Tanzania. A total of 40 informants were purposefully selected to participate in the study meanwhile a thematic analysis was
employed to analyse and manage the data. In order to produce indisputable data, indispensable cleanings, transcription,
coding, organizing, and theming were ascertained in the process. The findings reveal that, there is negative perceptions
towards students' dressing codes which resulted into ethical based discontent amongst Tanzanians on the dressing codes of
higher learning institutions' students meanwhile public comments to the legislative bodies to make a law or related policy
that will be implemented to regulate all kinds of undesirable dressing behavior in learning institutions.

Keywords: Politics, Dress code, Higher learning Institution, Public Perception, Students

\section{Background of the Study}

Politics of students' dressing codes and its impact on political and public perceptions in higher learning institutions is a contemporary discussion trending all over the world (Keohane, 2006). Originally, dress codes were first established in England to charity schools in the $16^{\text {th }}$ century where uniform dresses were often provided for poor children (Kidd, 1999). This got its extension to public schools later. Africa in particular, dress codes came into practice in $19^{\text {th }}$ century. Even so, since its inception, dress codes in developing countries have perceived differently from one culture to another (Hansen \& Madison, 2013).

In the past few years politics about the dressing codes in higher learning institutions attracted attention of policy makers and scholars, particularly in developing countries by start looking the way students' dress codes manipulate learning outcomes as well as the surrounding communities in which the institutions located. It is apparent that dressing politics in higher learning institution has significant impact on the way general public perceive it. For instance, dressing codes guidelines were established in Tanzanian higher learning institutions for the purpose of harmonizing dressing behavior. The reason for this particular establishment is that, learning institutions in Tanzania have been experiencing politics of dress codes, and dress codes violations due to inappropriate dressing on campuses and society (Mvungi, 2014).

The politics of fashions, designs and dressing styles across the globe appear to be the contributing factor towards unethical dressing behavior. Politics on students' dressing codes are now taking place in law-makers houses in developing countries and some of these countries have started making laws to regulate the prevailing situation. However, in some countries, a delayed reaction against dressing codes, has affected students' social ethical behavior in higher learning institutions and its outcomes have been manifested through students' personalities as in talking, wearing, walking, feeling and thinking. Today, in developing countries, it is quite easier to identify Students' ethical behavior by just looking at the dressing style which leads to predetermined student's character and respect (Hamilton, 2009; Mvungi, 2014).

Scholars (Allman, 2004; Keohane, 2006; Berry, 2011) indicate that university policy makers, students and professors in particular have a specific position among the political and public domain. Though higher learning institutions are training students to become potentials leaders, and acceptable members of the society their ethical behavior related to dressing is a challenge as result various state governments and educational institutions across the globe embarked on introduce sensitive rules to guide on campus dressing codes.

Studies (Holt, 1997; Mvungi, 2014; Edwards \& Marshall, 2020) debate that during the present dynamic age, there is probably another sphere of human activity being important to such an extent in which our values and life-styles are reflected more than they are in the clothes that we choose to wear. It is therefore dressing styles manifests to individual's behavior and life styles that may impede effective implementation and compliance to dress codes. Levine, Moreland \& Hausmann, (2005) suggest that in order to handle negative perception and politics by the community on the dressing behaviour, unwritten rules that certain styles may be approved or 
disapproved by the group. Members of the group are to follow and even pressured to dress in the same way. Clothing that does not conform to the groups standard and expectation be criticized and the pressure should be strong and cruel forcing people to either conform or be excluded from the group. Similarly (Fayokun, Adedeji, \& Oyebade, 2009) comment that, many higher institutions across the world, struggle with indecent dressing politics among the youths which is becoming the emblem of the modernity in general and the university campuses in particular.

Presently, dressing politics are cherished more in civilized world than in conservative world (Duggan, 2002). For instance, in Africa, it appears to be there some initiatives taken to harmonize the situation in higher learning institutions. In Nigeria most of the higher learning institution of learning faces this situation of indecent dressing among students (Fayokun, Adedeji, \& Oyebade, 2009). Asaju (2013) exposes that sexual gratification perpetuated in campuses was far more than that of the activities of the prostitutes in the hotels and other public social night clubs. No wonder that measures were to be taken to restore students' manhood, values and social ethics. The clothes we wear influence our ethical behavior, mood, personality, confidence, attitude and the way we interact with others as Schmalz (2000) says you are who you are dressed.

Wema (2016) asserts that at Morogoro municipal in Tanzania most of employees used to wear unacceptable dresses that violated revised dress code of 2007 despite the level of awareness they had and supervision provided by employers on issues of dressing code implementation. The increasing noise and politics about dressing codes appears to be perpetuated by some employees who are the products of higher learning institutions. Most higher learning institutions in Tanzania face the problems about students' dressing behavior. The problem is escalated by the so called dressing codes politics, due to this, managements of these institutions are in tireless efforts of to control the situation. Regulations concerning students' dress codes politics are established to guide students' way of dressing in almost all higher learning institutions in Tanzania. In the College of Business Education (CBE), the dress code was officially introduced in 2009 through the instrument called General Conduct, Disciplinary Proceedings, and Penalties of College of Business Education Students' By-Laws 2009 (Zembazemba, 2017). Moreover, the CBE Students' by-Laws (2015) the level of punishment for those dressing indecently depends on the frequency of the offence by the student.

In Dar es salaam University College of Education (DUCE), dress code is prescribed in students' by-laws of institutions to enhance discipline and self-respect to students as longer as proper dressing is a symbol of selfrespect as well as respecting others in 2015. However, there is no prescribed dress code for students in Dar es salaam University college of Education (DUCE). It is the responsibility of each student teacher to observe standards that subscribe to a degree of modesty and decency in both dress and manner (DUCE, 2015).

Dress code of the Saint John University of Tanzania (2012) shows that taking gowns or skirts hanging above the knees, transparent dresses of any kinds which are not supported by a reasonably heavy underskirt is a moral offence that may lead to penalty. The code also delineates clothes with slits above the knees, tightly fitting clothes, and skin tights, dresses exposing stomach, breasts, waist, thighs and such other clothes as tops, low cuts, pants of all kinds, over- adornment with neck-laces, bangles, and the like are strictly prohibited to be dressed at the campus (Wema, 2016; Zembazemba, 2017).

According to St Agustine University of Tanzania (SAUT) student by-laws (2015) indecently dressing of the student may lead to verbal, written warning or suspension for one year with approval of the disciplinary Committee. This indicates that the efforts to restore students' dressing behaviors in higher learning institutions in Tanzania are evident; however indecent dressing to students is still going on Despite the laid down rules that not only forbids indecent dressing in the College, but also stipulated punishments for offenders (Asaju, 2013; Mvungi, 2014).

\section{Statement of the Problem}

The benefits of standardized dress codes policy implemented and maintained over time appears to produce positive effects on student's dressing behavior towards political and public ethical perceptions. Hoekema (1994), Colby, Beaumont, Ehrlich \& Stephens (2003) and Quaye, Harper \& Pendakur (2019) assert that controlling students' dressing politics and ethics has positive benefits, including improved campus morale and reduced discipline violations, increased school pride and enhanced image of students and the institution in the community. It is on such grounds that trigger institutions to foster observation of decent dressing behaviors to their students. Dressing codes politics have resulted into established and implemented dressing guidelines in higher learning institutions in Tanzania to guide students' dressing and bringing a good image of a particular university as indicated in different by-laws such as SAUT, (2015); DUCE, (2015); SJUT (2013) \& CBE, 2015). 
Despite the dress codes and their stipulated implementations, indecent dressing behaviors of students are noticed. It is under this ground therefore this study intended to explore public perception towards students' dressing code in Tanzanian higher learning institutions to see why students do not comply with the dress codes policy despite their knowledge.

\section{Objectives of the Study}

The overall objective of this study was to explore political and public perceptions towards students' dressing codes in Tanzanian higher learning institutions that appeared to have impact on political, social and ethical behavior of the new generation in the community. In order to have comprehensive knowledge about the temperament and impact of students' dress codes to the community, the following specific objectives formed to explore key information as follows.

a. To examine political and public perceptions towards students' dressing code in Tanzanian higher learning institutions.

b. To identify strategies for effective implementation of dress code in higher learning institutions for positive change.

\section{Literature Review}

\section{Conceptualization of High learning Student's dressing codes}

Dressing codes politics, are politics related to dressing behavior of students in higher learning institutions and the way public feel offended traditionally, culturally, and ethically (Magolda, 2000). The wide ranging public dissatisfaction and discussion on the way student dress in higher learning institutions, attracts majority in public domain to have question, on moral, social and ethical behaviour of that particular social class. It is an emerging social knowledge that interested to understand how dressing behaviour influence policy perspectives and other related political and public debates.

The ongoing public discussion on dress codes in developing counties, Africa in particular, attracts policy makers to intervene by establishing and developing policy framework to guide higher learning communities on how to nurture students as well as surrounding communities. Dress codes as described by several researchers and scholars is a set of rules which are often written on hand books or by-laws with regard to dressing (Manwa, Ndamba \& Manwa, 2010; Jabbal, 2014). As public policy, dress codes signs, they might be put on postures in form of pictures illustrating types of dresses acceptable and not acceptable. Dress codes are meant to create harmony, personality or differentiate from one group to another for the sake of identity and successful production as in companies, public sectors and higher learning institutions such as Universities, Banks, and Parliament (Galadari, 2012; Cutts, Hooley \& Yates, 2015).

The politics of what to be worn in higher learning, draws attention of scholars in defining who is a student of that particular level. The perceived students of higher learning institutions are learners or scholars attending for short or long courses (Jamal, Ramlan, Karim, \& Osman, 2015). When they are at the learning environments they are trained to become professionals, self-esteemed, high valued, disciplined, expected state leaders, good parents, advisers, and trainers. They need to show these in and outside the learning environment. It is through students' personalities as in talking, dressing, walking, feeling and thinking a student can prove his or her acceptable social and ethical behavior (Lowery-Hart, \& Pacheco Jr, 2011). Dressing behavior is the most visible indicator in understanding students' behavioral development and a type of a future leader.

Studies (Malott, 2010; de Oliveira Faria, Gandolfi, \& Azevedo Moura, 2014; Norman, 2018) demonstrate that, although higher learning environments are places believed to change students' behavior, emotionally, intellectually, visionary, physically and morally, university lecturers are concentrating much on intellects only leaving other supporting knowledges aside especially dressing behavior which in turn creates conducive environment of learning. The primary technique proposed for students' awareness of the established dress codes at campuses is through students' by-laws and postures placed on boards (Workman, \& Cho, 2012). According to previous studies (Omede, 2011; Kaptein, 2011) some of the students appeared to have no enough knowledge about the impact of the dress codes and some had with least knowledge about the massages they conveyed as a result the general public tended to perceive them negatively.

Ndibalema, (2019) states that university students are not aware of the dress codes politics when they are at secondary schools for teaching practice, the interviewed school leader responds that female teachers showed a high violation of dressing code and that may be they were not taught at the University. Furthermore, 
Zembazemba (2017) give explanation on how students violated dress code at the campus despite their response that they were aware of the college dress codes. The problem is being aware that although the dress codes are existing it does not guarantee students to comply, it needs more knowledge of why should they comply, what if not and what does it add to their professions and life in whole.

In Tanzania, political and public and figures and students, become offended and judged by the choice of dresses they put on. It is very important subject as an individual is publically judged or perceived that way based on his/her appearance in public sphere. Despite the fact that dress codes is a creeping phenomenon into human ethical progress, dress codes appear to be given little chance in discussion compared with other academic issues (Blake, Butler, Lewis, \& Darensbourg, 2011). Therefore, educating an individual should involve teaching appropriate clothing for various events or occasions because the choice of dressing one makes affects his/her personality negatively or positively (Ruggerone, 2017).

\section{Students' Attitudes Towards Politics of Dress Codes In Higher Learning Institutions}

Attitude is an expression of feeling, beliefs and evaluation of those beliefs based on experience (Ajzen \& Fishbein, 2000). Students' attitudes reflect what students believe to be good or bad for them in their environments. Katz (1960) explains how dressing behavior and attitudes toward certain dressing guidelines have a close relationship since attitude plays a major role in reflecting dressing behavior. Students in higher learning institutions politicize that every person has an innate need to look good either professionally, showing status or become attractive (Etcoff, 2011). Therefore, students feel better about them when they dress to fit in with the crowd they associate. Their intention is to draw attention of people around through clothing (Frohard-Dourlent, 2016; Twigg, 2007).

Studies (Berry, 2011; Bain, 2012) indicate that, usually students get stumped on what to wear on constantly changing weather that students focus on style or comfort or both. When shopping for new dresses they consider fashion, affordability and comfort. Kees (2017) suggests that students should be made aware of the nonverbal massages their appearance conveys. We believe that educating the whole person includes teaching appropriate dress for various occasions. Our clothing choices we make should reflect respect and love for people through modest attire (Aries \& Seider, 2005).

Politically, as future leaders and parents, students should be helped to nurture their attitude towards dressing behavior as it has a futures implication to their diverse professional careers. A number of studies done on students' dress codes in Africa demonstrate how students from different universities are still dressing unauthorized and provocative dresses (Anku, 2016). Students' attitudes were seen to be one of the influential factors based on their experience and background from their child hood. Allman (2004) clothing behavior of children in homes does not reflect African culture and integrity. Parents don't discourage their children's indecent clothing and some buy for them and don't care of what the society may speak of them. Experience creates an individual's attitude toward certain behaviors.

Studies (Orenstein, 2013; Garber, 1997) divulge that today's university female students prefer dressing skinny trousers, if you asked why violating the dress codes they might be able to confidently respond that they don't think if they are not right because they have been dressing that for a long time and no one questioned. However, in modern liberal universities, studies portray how students dress provocatively in lecture rooms to an extent that you couldn't understand whether the campuses accommodating students or prostitutes (Mvungi, 2014; Siduna, 2017).

Mvungi (2014) argues that a dress is a true reflection of what an individual is, that means there is a close relationship between outside image and inner image. He also believes that dressing behavior is an indication of an individual's attitudes toward dressing standards. According to reasoned action theory (1967) attitude is determined by beliefs about outcomes and evaluation of those outcomes. In this regard dressing behavior may be positive or negative depending on what a student believes about outcomes of his/her dressing and evaluation of those dressing outcomes. Siduna (2017) studied students' attitudes towards dress codes and confirmed that conforming to college dress codes or policy related guidelines helped students gain respect, study comfortability and understanding who they are. When dress codes positively perceived students will conform and if negatively perceived will not. Students do not abide to dress codes policies because they see them as rigid restricting them from moving with the ever-changing world fashions.

\section{Public Perception Towards Students' Dress Codes In Higher Learning Institutions}


According to Broadbent (2013), Piaget (2013) and Myin (2016) perception means collection and interpretation of information from what we see, hear, feel, touch and smell based on our experience. This affects how people interact with the things as sources of information. Perception is also referred to as how an individual considers something to be based on background information or knowledge (Gulliver, Griffiths \& Christensen, 2010) What a person considers to be good or bad will act accordingly. University students consider themselves as grown people, self-independent with right to dresses of their choice (Lowe, Dillon, Rhodes \& Zwiebach, 2013). However, studies demonstrate that the public perception differs from what students tend to believe is right. Holistically, the Public eye see them dressed up in un-recommended clothing such as tight trousers, skirts, blouses, transparent dresses, skinny jeans, jeans with holes, shorts, trousers hanging under buttocks, min-skirts, dresses or skirts with excessive slit to mention few (Mandhachitara \& Piamphongsan, 2011).

Previous studies (Lowe, Dillon, Rhodes \& Zwiebach, 2013) demonstrate how parents and the public community support school dress code because it diminished chaos, conflicts, attendance offences, students' economic level distinction and enhanced learning and sense of belonging. This suggests that if students perceive dress code positively they are ready to change and comply to formal and ethical dress codes that do not irritate the public community. Formal dressed students were perceived honesty, of high status, sense of authority, and friendly with good characters (Witt \& Kerssen-Griep, 2011).

Scholars, Edwards \& Marshall (2020) comment that there was a high drop up of moral behaviors in most institutions and societies. The public perception is that if dressing codes is not moderated can destroy a society and person moral behaviour of an individual (Guglielmo \& Malle, 2010). The way students dress, generate positive or negative perception towards their living (Armstrong, Niinimäki, Kujala, Karell \& Lang, 2015). Dress plays an important role more than as an item of dressing rather it is also a symbol to mark status, age, behavior, ethnicity, socio-economic status, group or education status, thus students have to observe African values and culture (Moletsane, Mitchell \& Smith, 2012).

Previous studies (Berns, 2012) indicate that the public community perceived dress code as smartness, discipline and good image of the college. According to Rubinstein (2018) Tanzania is viewed as a conformist or traditional country. It is modest in many areas especially in choice of clothing. In public and political offices people get stopped at the gate if dressed indiscipline. Rubinstein (2018) added that if a lady is dressed in a tight or short dress is perceived to be seeking attention of rich men because their appearances cause temptation to both men and women. Wema (2016) believe that people perceive inappropriate clothing to their societal values as a source of sexual harassment. Therefore, negative perceptions towards dress codes make students wear indisciplined and prohibited dresses at the campuses and positive perceptions make them comply.

\section{Theoretical Perspective of the Study}

This study utilized the theory of reasoned action (1970) to test the influential factors for students' dressing behavior. The theory of reasoned action (TRA) uses two factors assumed to influence behavioral intention that is attitude and subjective norm (Kim, Kim \& Goh, 2011). The theory of reasoned action (TRA) suggests that there is a direct relationship between behavior and attitude of an individual (Yousafzai, Foxall \& Pallister, 2010). TRA predicts human behavior in general (Montaño \& Kasprzyk, 2015). Scholars have consider TRA to be the best predictor of intention to perform a particular behavior (Conner, 2020; Ali, Raza \& Puah, 2017). This mean that undesirable dressing codes portrays a predicable behavior of an individual. It is at this juncture, a future leader can easily be known, particularly in the way he/she reasons matters related to public domain. According to Conner, (2020) an individual's behavior can be determined by his/her intentional behavior which is also determined by attitude and subjective norms towards behavior. It is from this point of view that reasoning develops perceptions of various phenomenon that take place in our premises. Therefore, the theory of reasoned action provides a solid foundation in understanding the way public reasons, and perceive both ethical and unethical dressing codes of students in higher learning in Tanzania.

\section{Research Methodology}

This study exploited qualitative research methods. Qualitative research method refers to the techniques used to collect, analyze and interpret non-numerical data to get meaning for understanding the social life of the targeted population under study (Crossman, 2017). In order to collect and produce relevant data, the study used an in depth interview in collecting the data whereas 40 informants from 10 administrative regions in Tanzania were purposefully sampled to participate in the study. Since the study was curious in acquiring public perception on dressing behaviors of students in higher learning institutions in Tanzania, the researchers used the social 
demographic affiliated indigenous to identify, select and organize appointments and venues for the interviews. In the moment of in depth interview, tape recorders and note books were utilized to record and note down all essential information made by the informants. On the other hand, thematic analysis was used to analysis the data obtained from the in depth interview. According to Braun and Clarke (2019) thematic analysis is the best in scrutinizing and reporting patterns and themes within qualitative data, thus, the choice of this data analysis method was well thought out suitable and pertinent for this study.

\section{Research Findings}

The focus of this study was to explore the political and public perceptions on students' dressing codes in Tanzanian higher learning institutions. Demographically, the choice of participants was purposefully done in order to have equal gender representation of both male and female informants from the public population. Generally, the findings demonstrate that both female and male had negative perception towards students' dressing codes in higher learning institutions in Tanzania.

Table 1. Social demographic of informants

\begin{tabular}{|l|l|l|l|l|l|l|l|l|l|l|l|l|}
\hline Public Perceptions & \multicolumn{2}{|l|}{ Male } & \multicolumn{2}{l|}{ Female } & \multicolumn{2}{l|}{$\begin{array}{l}\text { Between } \\
\text { 18 to 50 of } \\
\text { age }\end{array}$} & \multicolumn{2}{l|}{$\begin{array}{l}\text { Between } \\
\text { 51 to 66 of } \\
\text { age }\end{array}$} & \multicolumn{2}{l|}{$\begin{array}{l}\text { Between } \\
\text { Home based } \\
\text { to secondary } \\
\text { education }\end{array}$} & $\begin{array}{l}\text { Between } \\
\text { collage } \\
\text { University } \\
\text { education }\end{array}$ \\
\hline $\begin{array}{l}\text { With positive } \\
\text { perception towards } \\
\text { dressing code }\end{array}$ & 4 & $10 \%$ & 2 & $5 \%$ & 10 & $25 \%$ & 2 & $5 \%$ & 5 & $12.5 \%$ & 12 & $30 \%$ \\
\hline $\begin{array}{l}\text { With negative } \\
\text { perception towards } \\
\text { dressing code }\end{array}$ & 16 & $40 \%$ & 18 & $45 \%$ & 14 & $35 \%$ & 14 & $35 \%$ & 15 & $37.5 \%$ & 8 & $20 \%$ \\
\hline
\end{tabular}

The findings reveal that students' dressing codes in the higher learning institutions has significant negative influence towards political and public and social ethical dressing behaviour in Tanzania. Majority of informant across social demographic categories presented above, confirmed to have negative perception towards students' dressing codes in the higher learning institutions whereas minority demonstrated to have positive or confidence towards students' dressing codes in the higher learning institutions.

Moreover, the findings reveal that $15 \%$ of both female and male informants confirmed to have positive perception towards students' dressing codes in the higher learning institutions whereas $85 \%$ of them have negative perception towards students' dressing codes in the higher learning institutions. Furthermore, the findings disclose that $30 \%$ of informants with the age between 18 to 65 plus, appeared to have positive perception towards students' dressing codes in the higher learning institutions meanwhile $70 \%$ of informants in this age category confirmed to have negative perception towards students' dressing codes in the higher learning institutions.

On the other hand, $42.5 \%$ of informants with education level ranging between home-based schooling to university have demonstrated to have confidence by perceiving positively students' dressing codes in the meantime $57.5 \%$ of the same education ranging category, have negative perception towards students' dressing codes in the higher learning institutions.

In summary, the findings from this study suggest that the political and public community in Tanzania has negative perception towards students' dressing codes in the higher learning institutions. Regardless of their age and education background, it is confirmed that the political and public opinion demonstrate that people are not satisfied with dressing behaviour in the higher learning institutions and that's why the government, learning institutions and legislative bodies are embarked on formulating dressing codes guidelines to minimize offenses related to this particular subject.

\section{Discussion}

The overall findings from this study indicate that majority of participants of the study confirmed to have negative perceptions towards students' dressing codes in higher learning institutions in Tanzania. Unethical students' dressing codes, appears to draw attention of more than $85 \%$ percent of the political and public community population. This is a significant segment of the population and it is an indicator that the community 
is not satisfied with the dressing codes of their beloved children and that's why there is a political pressure to handle this matter. The political and public negative perceptions surfaced as result of seeing students attired themselves in short skirts hanging above the knees, transparent dresses, tightly fitting clothes, and skin tights, dresses exposing stomach, breasts, waist, thighs and such other clothes as tops, low cuts, pants of all kinds, overadornment with neck-laces, bangles, half-nates dropped trousers as well as dramatic change in behavior regarding to talking, wearing, walking, feeling and thinking of students in the community. These words confirmed by one the male informant aged (51), he state that:

"I was not aware of what was taking place in the higher learning institutions until when I visited my daughter in one of the weekends last year. I was so much amazed to see young ladies clothed half naked, at my surprise, my daughter told me that, Dad this is a normal life here, especially on the weekend like this. I was speechless as they were many emerging in that particular manner. Ever since, I was so much discouraged, that why to me, this kind of students' dressing codes should seriously challenged by entire community"

The practical implication of these findings could be a stepping stone towards policy establishment or introduction of dressing codes' curriculum for higher learning institutions that will embrace and enshrine African traditional dressing culture that preserve norms and ethics which the community appears to debate about. Furthermore, the findings indicate that, it is not only Tanzanian public community which is facing this particular problem, also it appears that the same challenge is facing many other African countries including Nigeria, South Africa, and Kenya which already have dressing codes initiatives in place (Fayokun, Adedeji, \& Oyebade, 2009).

However, the findings unmasking $15 \%$ of the interviewed population had positive perception towards students' dressing codes in higher learning institutions. This implies that there some people in the public community who are against traditional ways of dress codes and they would wish to see students in higher learning institutions set free from all sorts of politics of dressing codes emerging in various higher learning institutions. This perception is confirmed by the informant aged (36) as she states below;

"Regardless of dress codes guidelines in the higher learning institutions, I am interested to see students freely doing things of their own. We are in the new era of fashions and creativity, why don't we give time to our children to cloth up into these fashions! It is a jealousy tendency to perceive others negatively all the time, especially when you are not interested in whatever they have worn. Essentially, this happens when you found yourself out of time! However, there is nothing new now, whatever is new now there was once old"

One of the most interesting aspects about these findings is that there some people in the political domain and public community, particularly those with the age ranging between 18 to 35 or with collage /University scholars appeared to have confidence and positive perception towards students' dressing codes. What reads in their mind is that, every generation has its own opportunity of being recognized and experiencing the world. In a similar manner, Brodar, Crosskey \& Thompson (2015) contend that to have judgmental perceptions on what people do wear is denying theme chances to maximize and exploit their potentials in the community. These findings sometimes inform us that there is a gap of knowledge and information between the new generation which appears to be liberal and the old generation which sounds conservative in these exceptionalities. Holistically, it was adults informants who were negatively perceived students' dressing codes as a new culture that intends to do away traditional of dressing. However, the youth age group appeared to cherish whatever seems to make happy, modernized and fashioned as a result it intensified dress codes politics in the community.

\section{Conclusion}

The study concludes that negative perceptions towards students' dressing codes politics in higher learning institutions still have significance influence in the political and public community in Tanzania. Even though minority appeared to have confidence in students' dress codes, this small segment of the political and public community do not defeat the reality that the community needs reform on students' dressing codes in higher learning institutions. Actually, it appears that there is a gap of knowledge and information between those who perceive this phenomena negatively and those who perceive it positively. The reasons behind these two perceptions is that there is no comprehensive and collective institutionalized policy mechanism to address this matter in the public community as result it has escalated challenges to not only students in higher learning institutions but also has spilled over to the young generation in the community. It is true that the ongoing life style and fashions across the globe has own impact on the dressing codes policies of students around the world; however, it the role of the policy and decision makers, and the community to identify applicable strategies that will embrace ethical dressing behavior in order to minimize negativity on the young generation in higher learning institutions. Despite the fact that Tanzania has a dress codes guideline, the state policy and decision makers, parents and other stakeholders are responsible for maintaining ethical dressing behaviour by assisting the 
government to see how it can properly establish and implement a comprehensive dress code curriculum or any other comprehensive dress codes policy in regard to higher learning institutions so that to harmonize political and public perceptions.

\section{References}

1. Ajzen, I., \& Fishbein, M. (2000). Attitudes and the attitude-behavior relation: Reasoned and automatic processes.

2. Ali, M., Raza, S. A., \& Puah, C. H. (2017). Factors affecting to select Islamic credit cards in Pakistan: the TRA model. Journal of Islamic Marketing.

3. Allman, J. M. (Ed.). (2004). Fashioning Africa: power and the politics of dress. Indiana University Press.

4. Anku, J. O. C. E. L. Y. N. (2016). The effects of women's suggestive dressing on men's behaviour and judgement. (case study in some selected universities in Ghana) (Doctoral dissertation, University of Education, Winneba).

5. Aries, E., \& Seider, M. (2005). The interactive relationship between class identity and the college experience: The case of lower income students. Qualitative Sociology, 28(4), 419-443.

6. Armstrong, C. M., Niinimäki, K., Kujala, S., Karell, E., \& Lang, C. (2015). Sustainable product-service systems for clothing: exploring consumer perceptions of consumption alternatives in Finland. Journal of Cleaner production, 97, 30-39.

7. Asaju, K. (2013). Assessment of Students' Perception of Dress Code in Tertiary Institutions in Nigeria: A Study of Federal College of Education Zaria. IOSR Journal of Research \& Method in Education, 2(1), 1-8.

8. Bain, K. (2012). What the best college students do. Harvard University Press.

9. Berns, R. M. (2012). Child, family, school, community: Socialization and support. Nelson Education.

10. Berry, B. (Ed.). (2011). Teaching 2030: What we must do for our students and our public schools: Now and in the future. Teachers College Press.

11. Blake, J. J., Butler, B. R., Lewis, C. W., \& Darensbourg, A. (2011). Unmasking the inequitable discipline experiences of urban Black girls: Implications for urban educational stakeholders. The Urban Review, 43(1), 90-106.

12. Braun, V., \& Clarke, V. (2019). Reflecting on reflexive thematic analysis. Qualitative Research in Sport, Exercise and Health, 11(4), 589-597.

13. Broadbent, D. E. (2013). Perception and communication. Elsevier.

14. Brodar, K. E., Crosskey, L. B., \& Thompson Jr, R. J. (2015). The relationship of self-compassion with perfectionistic self-presentation, perceived forgiveness, and perceived social support in an undergraduate Christian community. Journal of Psychology and Theology, 43(4), 231-242.

15. Colby, A., Beaumont, E., Ehrlich, T., \& Stephens, J. (2003). Educating citizens: Preparing America's undergraduates for lives of moral and civic responsibility (Vol. 6). John Wiley \& Sons.

16. Conner, M. (2020). Theory of planned behavior. Handbook of Sport Psychology, 3.

17. Crossman, A. (2017). Purposive Sampling Definition and Types.

18. Cutts, B., Hooley, T., \& Yates, J. (2015). Graduate dress code: How undergraduates are planning to use hair, clothes and make-up to smooth their transition to the workplace. Industry and Higher Education, 29(4), 271-282.

19. De Oliveira Faria, Y., Gandolfi, L., \& Azevedo Moura, L. B. (2014). Prevalence of risk behaviors in young university students. Acta Paulista de Enfermagem, 27, 591-595.

20. Duggan, L. (2002). The new homonormativity: The sexual politics of neoliberalism. Materializing democracy: Toward a revitalized cultural politics, 10, 9780822383901-007.

21. Edwards, T. K., \& Marshall, C. (2020). Undressing policy: a critical analysis of North Carolina (USA) public school dress codes. Gender and Education, 32(6), 732-750.

22. Etcoff, N. (2011). Survival of the prettiest: The science of beauty. Anchor.

23. European review of social psychology, 11(1), 1-33.

24. Fayokun, K. O., Adedeji, S. O., \& Oyebade, S. A. (2009). Moral crisis in higher institutions and the dress code phenomenon. Online Submission, 6(2), 58-66.

25. Frohard-Dourlent, H. (2016). 'I don't care what's under your clothes': the discursive positioning of educators working with trans and gender-nonconforming students. Sex education, 16(1), 63-76.

26. Galadari, A. (2012). Behind the veil: Inner meanings of women's Islamic dress code. The Journal of Interdisciplinary Social Sciences, 6(11), 115-125.

27. Garber, M. (1997). Vested interests: Cross-dressing and cultural anxiety. Psychology Press. 
28. Guglielmo, S., \& Malle, B. F. (2010). Can unintended side effects be intentional? Resolving a controversy over intentionality and morality. Personality and social psychology bulletin, 36(12), 1635 1647.

29. Gulliver, A., Griffiths, K. M., \& Christensen, H. (2010). Perceived barriers and facilitators to mental health help-seeking in young people: a systematic review. BMC psychiatry, 10(1), 113.

30. Hamilton, J. (Ed.). (2009). Dress codes in schools. Greenhaven Publishing LLC.

31. Hansen, K. T., \& Madison, D. S. (Eds.). (2013). African Dress: fashion, agency, performance. A\&C Black.

32. Hoekema, D. A. (1994). Campus rules and moral community: In place of in loco parentis. Rowman \& Littlefield.

33. Holt, D. B. (1997). Poststructuralist lifestyle analysis: Conceptualizing the social patterning of consumption in postmodernity. Journal of Consumer research, 23(4), 326-350.

34. Jabbal, A. (2014). Medical student dress code in the orthopaedic out-patient department. The clinical teacher, 11(7), 507-511.

35. Jamal, A. A. A., Ramlan, W. K., Karim, M. A., \& Osman, Z. (2015). The effects of social influence and financial literacy on savings behavior: A study on students of higher learning institutions in Kota Kinabalu, Sabah. International Journal of Business and Social Science, 6(11), 110-119.

36. Kaptein, M. (2011). Toward effective codes: Testing the relationship with unethical behavior. Journal of Business Ethics, 99(2), 233-251.

37. Katz, D. (1960). The functional approach to the study of attitudes. Public opinion quarterly, 24(2), 163204.

38. Kaufman, G. F., \& Libby, L. K. (2012). Changing beliefs and behavior through experience-taking. Journal of personality and social psychology, 103(1), 1.

39. Keohane, N. O. (2006). Higher ground: Ethics and leadership in the modern university. Duke University Press.

40. Kidd, A. J. (1999). State, Society and the Poor in Nineteenth-Century England: In Nineteenth-Century England. Macmillan International Higher Education.

41. Kim, Y. H., Kim, M., \& Goh, B. K. (2011). An examination of food tourist's behavior: Using the modified theory of reasoned action. Tourism management, 32(5), 1159-1165.

42. Levine, J. M., Moreland, R. L., \& Hausmann, L. R. (2005). Managing group composition: Inclusive and exclusive role transitions. The social psychology of inclusion and exclusion, 137-160.

43. Lowe, S. R., Dillon, C. O., Rhodes, J. E., \& Zwiebach, L. (2013). Defining adult experiences: Perspectives of a diverse sample of young adults. Journal of Adolescent Research, 28(1), 31-68.

44. Lowery-Hart, R., \& Pacheco Jr, G. (2011). Understanding the first-generation student experience in higher education through a relational dialectic perspective. New Directions for Teaching and Learning, 2011(127), 55-68.

45. Magolda, P. M. (2000). The campus tour: Ritual and community in higher education. Anthropology \& Education Quarterly, 31(1), 24-46.

46. Mallya, A., Mensah, F. M., Contento, I. R., Koch, P. A., \& Barton, A. C. (2012). Extending science beyond the classroom door: Learning from students' experiences with the Choice, Control and Change (C3) curriculum. Journal of Research in Science Teaching, 49(2), 244-269.

47. Malott, C. (2010). Policy and research in education: A critical pedagogy for educational leadership (Vol. 4). Peter Lang.

48. Mandhachitara, R., \& Piamphongsan, T. (2011). Professional women's variety-seeking behavior in fashion clothing: New York City and London. Academy of Marketing Studies Journal, 15(1), 23.

49. Manwa, L., Ndamba, G. T., \& Manwa, L. (2010). A gendered dress code and how it influences the choice of dress by women in Zimbabwe. Journal of African studies and development, 2(6), 144-149.

50. Montaño, D. E., \& Kasprzyk, D. (2015). Theory of reasoned action, theory of planned behavior, and the integrated behavioral model. Health behavior: Theory, research and practice, 70(4), 231.

51. Mvungi, E. E. (2014). Dressing styles and its social impacts in higher learning institutions in Tanzania: a case of the University of Dodoma (Doctoral dissertation, The University of Dodoma).

52. Myin, E. (2016). Perception as something we do. Journal of Consciousness Studies, 23(5-6), 80-104.

53. Ndibalema, P. (2019). Professional Integrity Among Pre-Service Teachers During Teaching Practice: Experience from School Leaders in Misungwi District, Tanzania. Teacher Education and Curriculum Studies, 4(1), 9.

54. Norman, Z. D. (2018). Exploring the Effect of Service Learning Experiences on Students' Servant Leadership and Cultural Sensitivity. Gonzaga University.

55. Omede, J. (2011). Indecent dressing on campuses of higher institutions of learning in Nigeria: Implications for counseling. Journal of Emerging Trends in Educational Research and policy studies, 2(4), 228-233 
56. Orenstein, P. (2013). Schoolgirls: Young women, self esteem, and the confidence gap. Anchor.

57. Piaget, J. (2013). The mechanisms of perception. Routledge.

58. Quaye, S. J., Harper, S. R., \& Pendakur, S. L. (Eds.). (2019). Student engagement in higher education: Theoretical perspectives and practical approaches for diverse populations. Routledge.

59. Rubinstein, R. (2018). Dress codes: Meanings and messages in American culture. Routledge.

60. Ruggerone, L. (2017). The feeling of being dressed: affect studies and the clothed body. Fashion theory, 21(5), 573-593.

61. Schmalz, K. J. (2000). Marketing yourself, part 2: the unwritten dress code: how to dress for the job interview. Health Promotion Practice, 1(3), 229-233.

62. Siduna, B. (2017). Student sexual harassment at a Rural University in South Africa: a case study of the University of Venda (Doctoral dissertation).

63. Sustainable product-service systems for clothing: exploring consumer perceptions of consumption alternatives in Finland. Journal of Cleaner production, 97, 30-39.

64. Twigg, J. (2007). Clothing, age and the body: a critical review. Ageing \& Society, 27(2), 285-305.

65. Wema, A. (2016). Implementation of dressing code at Morogoro municipal council (Doctoral dissertation, Mzumbe University).

66. Witt, P. L., \& Kerssen-Griep, J. (2011). Instructional feedback I: The interaction of facework and immediacy on students' perceptions of instructor credibility. Communication Education, 60(1), 75-94.

67. Workman, J. E., \& Cho, S. (2012). Gender, fashion consumer groups, and shopping orientation. Family and Consumer Sciences Research Journal, 40(3), 267-283.

68. Yousafzai, S. Y., Foxall, G. R., \& Pallister, J. G. (2010). Explaining internet banking behavior: theory of reasoned action, theory of planned behavior, or technology acceptance model?. Journal of applied social psychology, 40(5), 1172-1202.

69. Zembazemba, R. D. (2017). Educational assessment practices in Tanzania: A critical reflection. Business Education Journal, 1(3). 